\title{
Early stenosis of Medtronic Mosaic bioprosthesis in the aortic position
}

\author{
Sheen Peeceeyen, MCh, Christopher Cao, BSc (Med), MBBS, Gary Fermanis, MD, FRACS, and \\ Con Manganas, MD, FRACS, Sydney, Australia
}

The Medtronic Mosaic valve (Medtronic, Inc, Minneapolis, Minn) is a third-generation stented porcine bioprosthesis combining physiologic fixation and $\alpha$-amino-oleic acid antimineralization treatment to improve hemodynamic performance and durability. ${ }^{1}$ Despite encouraging short-term and midterm clinical results, however, there has been a heightened interest in the safety and efficacy of this device after a recent case series study of early valve failure resulting from an unknown cause. ${ }^{2}$ We present here 2 case reports of early structural valve dysfunction after implantation of the Mosaic valve in the aortic position.

\section{CLINICAL SUMMARIES}

\section{Patient 1}

A 74-year-old man with severe aortic insufficiency and double-vessel coronary artery disease underwent an aortic valve replacement with a 25-mm Medtronic Mosaic bioprosthesis combined with two coronary artery bypass grafts. His postoperative gradient was $16.5 \mathrm{~mm} \mathrm{Hg}$, with an indexed effective orifice area (EOA) of $0.90 \mathrm{~cm}^{2} / \mathrm{m}^{2}$. The patient had an uneventful recovery and was discharged on a regimen of warfarin for 3 months with a therapeutic international normalized ratio of 2.0 to 3.0. Subsequently, his anticoagulation regimen was altered to aspirin alone.

The patient showed marked symptoms 18 months after surgery. Repeated echocardiography revealed a peak gradient of $76 \mathrm{~mm} \mathrm{Hg}$ across the aortic bioprosthesis with restricted leaflet mobility. In view of the severe symptoms and echocardiographic findings, the patient underwent reoperation. The original Mosaic valve was explanted and replaced with a $27-\mathrm{mm}$ St Jude mechanical valve (St Jude Medical, Inc, St Paul Minn). Intraoperatively, the leaflets of the Mosaic bioprosthesis appeared thickened and

\footnotetext{
From the Department of Cardiothoracic Surgery, St George Hospital, Sydney, Australia.

Disclosures: Authors have nothing to disclose with regard to commercial support. The Medtronic Mosaic valve is manufactured by Medtronic, Inc, Minneapolis, Minn. Received for publication Aug 15, 2011; revisions received Sept 28, 2011; accepted for publication Oct 20, 2011; available ahead of print Oct 21, 2011.; available ahead of print Nov 21, 2011

Address for reprints: Con Manganas, MD, FRACS, Department of Cardiothoracic Surgery, St George Hospital, Sydney, Australia (E-mail: conmanganas@hotmail. com).

J Thorac Cardiovasc Surg 2012;143:e13-4

0022-5223/\$36.00

Crown Copyright (C) 2012 Published by Elsevier Inc. on behalf of The American Association for Thoracic Surgery
}

fibrotic, with some fibrinous substance on the aortic aspects of the leaflets. Histopathologic examination reported fibrinoid material on the surfaces of the leaflets. The patient had an excellent outcome after the second valve implantation and was discharged home after an uneventful recovery.

\section{Patient 2}

A 62-year-old woman who presented with severe aortic stenosis and moderate aortic regurgitation underwent an aortic valve replacement with a $23-\mathrm{mm}$ Medtronic Mosaic valve. She had an indexed EOA of $0.83 \mathrm{~cm}^{2} / \mathrm{m}^{2}$. After an unremarkable postoperative course, she underwent routine follow-up with repeated echocardiography at regular intervals. Three years after the initial surgery, echocardiography demonstrated a mean prosthetic gradient of $13 \mathrm{~mm} \mathrm{Hg}$ with no significant abnormalities. At 5 postoperative years, however, the mean gradient was found to be $32 \mathrm{~mm} \mathrm{Hg}$ and the peak gradient $59 \mathrm{~mm} \mathrm{Hg}$, with evidence of moderate aortic regurgitation. Echocardiography also demonstrated a bright echodense lesion at the tip of the noncoronary cusp, suggestive of calcification. At the same time, the patient showed a recrudescence of symptoms and underwent reoperative aortic valve replacement with a Carbomedics prosthesis (SORIN GROUP USA, Inc, Arvada, Colo). This patient was also discharged home after an uneventful recovery. The explanted Medtronic Mosaic valve was found to be severely calcified.

\section{DISCUSSION}

Lawton and colleagues ${ }^{2}$ reported 4 cases of early stenosis from a cohort of 106 patients who underwent aortic valve replacement with the Mosaic bioprosthesis. The indexed EOA for these patients ranged from 0.76 to 0.89 $\mathrm{cm}^{2} / \mathrm{m}^{2}$, and early stenosis was identified 3 to 44 months after implantation. Lawton and colleagues ${ }^{2}$ were not able to determine the pathophysiology of this early valvular dysfunction but excluded patient-prosthesis mismatch as a possible cause because the indexed EOA was greater than $0.75 \mathrm{~cm}^{2} / \mathrm{m}^{2}$ in these 4 patients. Jamieson and coworkers ${ }^{3}$ responded to this report by highlighting that only 2 of the 4 patients had undergone implantation of the Mosaic valves at the reporting center. In addition, after reviewing the photographic, pathologic, and radiographic 
evidence of the explanted valves, they concluded that 2 of the bioprostheses were thrombosed and that the other 2 had coagulated blood on the outflow of the cusps and thus should not be classified as demonstrating structural valve dysfunction. This view was not shared by Flameng and associates, ${ }^{4}$ however, who hypothesized that early stenotictype valvular dysfunction in the 4 reported cases was perhaps related to patient-prosthesis mismatch or turbulent transvalvular flow. Their definition of moderate patientprosthesis mismatch for patients with an indexed EOA of less than 0.85 has since been challenged by Jamieson and colleagues. ${ }^{5}$

We have presented the cases of 2 patients with early stenotic valve failure who did not have any evidence of patient-prosthesis mismatch, and had postoperative indexed EOAs of $0.90 \mathrm{~cm}^{2} / \mathrm{m}^{2}$ and $0.83 \mathrm{~cm}^{2} / \mathrm{m}^{2}$. In addition, the explanted valves did not reveal any pannus formation or histologic evidence of thrombosis, although thrombosis could not be ruled out in the first case on the basis of the available evidence. Importantly, there was no evidence of subtherapeutic anticoagulation or procoagulant states, and our patients had normal renal function, without any documented hypercalcemic syndromes. After detailed pathologic examination, it remains unclear what caused the early valvular dysfunction of the Mosaic bioprostheses in our patients. In view of our findings, however, we believe that there is a need for clinical vigilance with regular echocardiographic follow-up in patients who have had implantation of Mosaic aortic bioprosthetic valves.

\section{References}

1. Fradet GJ, Bleese N, Burgess J, Cartier PC. Mosaic valve international clinical trial: early performance results. Ann Thorac Surg. 2001;71(5 Suppl):S273-7.

2. Lawton JS, Moazami N, Pasque MK, Moon MR, Damiano RJ Jr. Early stenosis of Medtronic Mosaic porcine valves in the aortic position. J Thorac Cardiovasc Surg. 2009;137:1556-7.

3. Jamieson WR, Fradet GJ. Aortic bioprosthesis - avoid obstructive properties due to thrombosis as altered durability due to structural valve deterioration. J Thorac Cardiovasc Surg. 2010;139:1354.

4. Meuris B, Flameng W. Relation between hemodynamic behavior and occurrence of early stenotic failure of bioprostheses. J Thorac Cardiovasc Surg. 2010;140: 1200 .

5. Jamieson WR, Fradet GJ. Relation between hemodynamic behavior and occurrence of early stenotic failure of bioprostheses: reply to the editor. J Thorac Cardiovasc Surg. 2010;140:1200-1.

\title{
Saphenous vein graft bronchopulmonary fistula after coronary artery bypass grafting presenting as chronic cough and subsequent massive hemoptysis
}

\author{
Elizabeth Belcher, MRCP, FRCS, PhD, ${ }^{\mathrm{a}}$ Edward Townsend, FRCS, ${ }^{\mathrm{a}}$ and Fabio De Robertis, MD, ${ }^{\mathrm{b}}$ London, \\ United Kingdom
}

Aortocoronary conduit bronchopulmonary fistula is a rare, potentially lethal complication seen after coronary artery bypass grafting $(\mathrm{CABG})$. The ideal diagnostic modality in such cases is not established. We present a case of earlyonset aortocoronary conduit bronchopulmonary fistula diagnosed by coronary angiography and immediate noncontrast computed tomography $(\mathrm{CT})$ in a patient with massive hemoptysis 8 weeks after CABG.

\footnotetext{
From the Departments of Thoracic Surgery ${ }^{\mathrm{a}}$ and Cardiac Surgery, ${ }^{\mathrm{b}}$ Harefield Hospital, London, United Kingdom.

Disclosures: Authors have nothing to disclose with regard to commercial support.

Received for publication Sept 4, 2011; revisions received Sept 24, 2011; accepted for publication Oct 20, 2011; available ahead of print Nov 21, 2011.

Address for reprints: Fabio De Robertis, MD, Department of Cardiac Surgery, Harefield Hospital, Hill End Rd, Harefield, Middlesex, UB9 6JH, UK (E-mail: f.derobertis@ rbht.nhs.uk).

J Thorac Cardiovasc Surg 2012;143:e14-6

$0022-5223 / \$ 36.00$

Copyright (C) 2012 by The American Association for Thoracic Surgery doi:10.1016/j.jtcvs.2011.10.042
}

\section{CLINICAL SUMMARY}

A 75-year-old woman underwent elective CABG. Conduits were fashioned from left internal thoracic artery to left anterior descending coronary artery and long saphenous vein graft to posterior descending coronary artery. The ascending aorta was noted to be thin walled and dilated, measuring $3.6 \mathrm{~cm}$. On removal of the cardioplegia cannula from the ascending aorta, a complex $2-\mathrm{cm}^{2}$ tear was noted. Control of this area was undertaken by fashioning the proximal aorta-saphenous vein graft anastomosis in an oversized manner.

At follow-up, the patient was noted to have acquired a chronic cough. At 8 postoperative weeks, the patient had sudden significant hemoptysis. Contrast chest CT demonstrated a filling defect in the bronchus intermedius, consistent with hemorrhage, retrosternal fluid collection, and opacification within the medial portion of the right upper lobe (Figure 1, A). Rigid bronchoscopy showed large amounts of blood throughout the tracheobronchial tree but no active bleeding point. Coronary angiography 